\title{
STOMACH
}

\section{Influence of sex and Helicobacter pylori on development and healing of gastroduodenal lesions in non-steroidal anti-inflammatory drug users}

\author{
C J Hawkey, I Wilson, J Næsdal, G Långström, A J Swannell, N D Yeomans
}

See end of article for authors' affiliations

.....................

Correspondence to: C J Hawkey, Division of Gastroenterology, University Hospital Nottingham, Queen's Medical Centre Nottingham NG7 2UH, UK; cj.hawkey@nottingham.ac.uk

Accepted for publication 26 November 2001

\begin{abstract}
Background and aims: Factors predisposing to endoscopic ulcer formation or healing with non-steroidal anti-inflammatory drugs (NSAIDs) have not been well defined.

Methods: We used multivariate analysis of data from three large similar trials to identify factors associated with endoscopic lesions and healing. We compared the effectiveness of omeprazole $20 \mathrm{mg}$ and $40 \mathrm{mg}$ daily, misoprostol $200 \mu \mathrm{gg}$ four times daily, and ranitidine $150 \mathrm{mg}$ twice daily in healing ulcers and erosions at different sites and in patients who were Helicobacter pylori positive and negative.

Results: Older age, past ulcer history, rheumatoid arthritis, and $H$ pylori infection were significantly associated with ulcers. Duodenal ulcer was significantly more likely than gastric ulcer with a past ulcer history (odds ratio 1.59, 1.16-2.17), H pylori infection $(1.4,1.04-1.92)$, and male sex $(2.35,1.75-$ $3.16)$ while female sex, older age ( $\geqslant 60$ years: $1.39,1.03-1.88)$, and higher NSAID dose (>1 defined daily dose: 1.57, 1.16-2.14) were associated with gastric ulceration. Sex differences were seen in both $\mathrm{H}$ pylori positive and negative patients. Gastric and duodenal ulcer healing was significantly faster with omeprazole $20 \mathrm{mg}$ than with misoprostol $200 \mu \mathrm{g}$ four times daily or ranitidine 150 $\mathrm{mg}$ twice daily although misoprostol was more effective at healing erosions. Gastric ulcer healing was slower with large ulcers $(0.37,0.25-0.54$ for $>10 \mathrm{~mm} v 5-10 \mathrm{~mm})$ or a past ulcer history $(0.51$, $0.34-0.76)$, and faster with $H$ pylori infection $(1.55,1.06-2.29)$, especially with acid suppression (72\% v $37 \%$ at four weeks with ranitidine).

Conclusions: Among NSAID users, $\mathrm{H}$ pylori and male sex independently increase the likelihood of duodenal ulceration. $H$ pylori infection does not affect duodenal ulcer healing and enhances gastric ulcer healing by ranitidine and possibly other acid suppressing treatments.
\end{abstract}

$\mathrm{N}$ on-steroidal anti-inflammatory drugs (NSAIDs) are a major cause of morbidity and mortality among users. Epidemiological data suggest that they increase the risk of ulcer complications and death by $3-10$-fold. ${ }^{1-3}$ Recent estimates of death rates are up to 2000 in the $\mathrm{UK}^{5}$ and 16500 in the USA. ${ }^{67}$ Endoscopic studies of patients taking NSAIDs chronically have shown a point prevalence for ulcer of approximately $20 \% .^{8-10}$

Almost all controlled epidemiological studies of risk factors concern ulcer complications,,$^{1-71-13}$ where factors leading to bleeding or perforation are influences additional to those leading to ulceration. Until recently, ${ }^{14-17}$ endoscopic studies with ulcer as an end point have been relatively small..$^{8-10}$ We have completed a programme of clinical trials involving more than 2000 patients using NSAIDs. ${ }^{18-22}$ The primary purpose of these studies was to investigate the role of omeprazole for the healing and prevention of NSAID associated ulcers and erosions. However, our database comprises the largest cohort of NSAID patients with endoscopic lesions who have been intensively and prospectively studied by endoscopy. Moreover, patients were actively recruited, resulting in a less selected population than if this had been done in response to clinical symptoms. Because of the potential for valid generalisation, we therefore used our database to investigate which factors were associated with specific endoscopic findings at baseline and with treatment success during healing of ulcers and erosions.

\section{METHODS}

Source of data

Trials

Data were gathered principally from three large multicentre trials (fig 1). The OMNIUM (Omeprazole versus Misoprostol for NSAID Induced Ulcer Management) trial compared omeprazole $20 \mathrm{mg}$ once daily, omeprazole $40 \mathrm{mg}$ once daily, and misoprostol $200 \mu \mathrm{g}$ four times daily as healing agents in patients found at screening endoscopy to have a gastric or duodenal ulcer or numerous $(>10)$ erosions in either the stomach or duodenum. ${ }^{19}$ The ASTRONAUT (Acid Suppression Trial: Ranitidine or Omeprazole for NSAID Associated Ulcer Treatment) study enrolled similar patients into a trial with an identical protocol that compared omeprazole $20 \mathrm{mg}$ once daily, omeprazole $40 \mathrm{mg}$ once daily, and ranitidine $150 \mathrm{mg}$ twice daily. ${ }^{19}$ Following successful treatment, patients in these studies were re-randomised to maintenance treatment with omeprazole $20 \mathrm{mg}$, misoprostol $200 \mu \mathrm{g}$ twice daily, or placebo (OMNIUM study), or to omeprazole $20 \mathrm{mg}$ or ranitidine 150 mg twice daily (ASTRONAUT study), and followed with routine endoscopy at one, three, and six months. In some of the centres participating in the OMNIUM study, patients that were ineligible because they had no ulcer and $\leqslant 10$ erosions in either stomach or duodenum were entered into a third study, the OPPULENT (Omeprazole versus Placebo as Prophylaxis against Ulcers or Erosions from NSAID Treatment) study. ${ }^{21}$ This was a comparison of omeprazole and placebo as prophylaxis, without an initial healing phase. Its design was identical to the maintenance phase of the OMNIUM and ASTRONAUT studies, specifically to allow data from these dual participation centres to be combined and to allow valid comparisons between trials. Patients in the SCUR ${ }^{18}$ study were not included

Abbreviations: NSAIDs, non-steroidal anti-inflammatory drugs; OR, odds ratio; DDD, defined daily dose. 


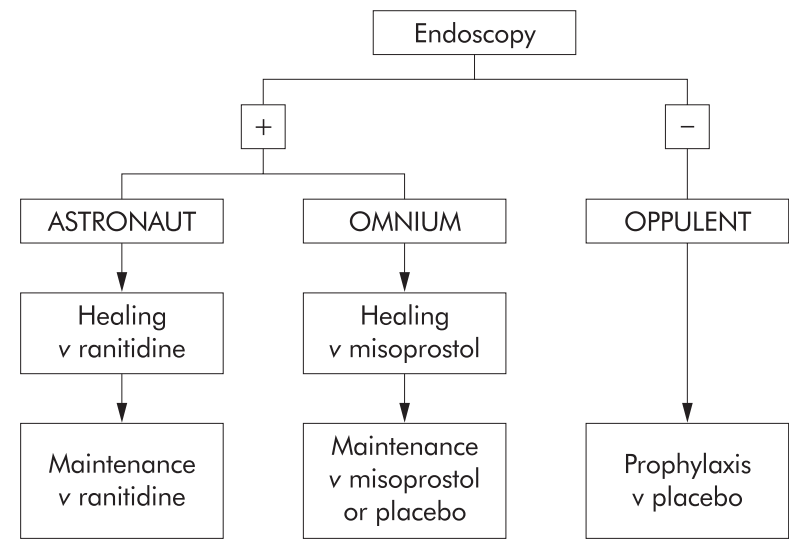

Figure 1 Outline of the trials that acted as the source of patients for analysis. Endoscopy positive is defined as an ulcer or more than 10 erosions present in either the stomach or duodenum. OPPULENT patients were enrolled from centres participating in the OMNIUM study. However, not all OMNIUM participants also participated in the OPPULENT study.

in our analyses because there was no baseline endoscopy. Patients in the HELP study ${ }^{22}$ were not included in the baseline analysis reported in this paper because they were a selected group, but relapse data are analysed in an accompanying paper [ see page 336$]^{23}$

Patient eligibility

With the exception of the endoscopic findings that directed patients in the dual participation centres into either the OMNIUM or OPPULENT study, the eligibility criteria were the same for all trials. Patients could participate if they were 18-85 years of age and had any condition requiring continuous treatment with oral or rectal NSAIDs provided this was above a predetermined minimal dose for each individual NSAID. Patients were excluded from participation if they had clinically important gastrointestinal bleeding, pyloric stenosis, or a history of gastric surgery or gastrointestinal disorders that might impair absorption of the study drugs. Patients taking corticosteroids at a dose $\leqslant 10 \mathrm{mg}$ prednisolone (or its equivalent) were allowed to enter the studies but those taking higher doses were excluded.

\section{Recruitment and definition of patient populations}

Potentially suitable patients were approached in primary care and rheumatological clinics. The purpose and nature of the trial was explained to them and those interested in participation underwent endoscopy. Most analyses reported in this paper concern the 1456 patients analysed in the OMNIUM and ASTRONAUT studies (designated cohort 1). Data from the dual participation centres that enrolled patients with ulcers or numerous erosions into the OMNIUM study and those with lower levels of injury into the OPPULENT study were used to assess the prevalence of baseline lesions across a representative range of NSAID users that was designated cohort 2.

\section{Conduct of the trials}

At trial entry, demographic and endoscopic data were collected systematically and identically for all of the trials. At endoscopy, lesions that were breaks in the mucosa with a diameter $\geqslant 3 \mathrm{~mm}$ and unequivocal depth were classified as ulcers. Smaller or shallower mucosal breaks were classified as erosions. Following endoscopy, patients eligible for the OMNIUM and ASTRONAUT trials were randomised to blinded trial treatment and endoscoped after four and, if unhealed, eight weeks. If treatment had not been successful by this time, they were allocated further open treatment with omeprazole $40 \mathrm{mg}$ daily and endoscoped at 12 and, if unhealed, 16 weeks. Patients continued to take their NSAIDs throughout the trial. Patients entering the OPPULENT trial also continued their NSAIDs and received omeprazole or placebo on a randomised double blind basis.

\section{Statistical approach}

Risk modifiers for the presence of clinically significant lesions at baseline were assessed by odds ratios (OR), together with their 95\% confidence intervals (CI). These were calculated using unconditional multiple logistic regression, fitted by the method of maximum likelihood to allow for several possible confounding factors. ${ }^{24}$ The terms included in the regression model for each end point are described below. Risk modifiers for overall treatment success and for healing of specific lesions during the trials were evaluated by a similar approach. A proportional odds model was used with graded time of healing (four weeks/eight weeks/unhealed) as the dependent variable.

\section{End points analysed}

Baseline lesions

Using data from cohort 2, we investigated whether patients found with sufficiently high levels of baseline pathology to enter the OMNIUM study differed from those who entered into the OPPULENT study because they had lower levels of gastroduodenal injury. The factors investigated were identified prospectively and comprised age, sex, smoking status, indication for NSAID, past history of dyspepsia, past history of peptic ulcer, Helicobacter pylori status, number of defined daily doses (DDD) of NSAIDs taken per day, ${ }^{25}$ and concomitant steroid use. We next analysed the much larger data set of cohort 1, comprising patients with clinically significant baseline lesions, to investigate whether there were differences between those with gastric ulcers, duodenal ulcers, or only erosions. The same statistical approach was used as for the comparison of clinically significant versus lesser lesions, and the same factors were entered into the multivariate analysis.

\section{Treatment success and ulcer healing}

Treatment success was the primary end point of both the OMNIUM and ASTRONAUT studies and was a composite of endoscopic healing and dyspeptic symptom control. To achieve treatment success, patients had to have no ulcer and $<5$ erosions in either the stomach or duodenum, and to have no more than mild dyspepsia. This composite end point was chosen to reflect the range of effects of NSAIDs in patients. Because only 13 of 1456 patients failed due to symptoms alone, it was possible to analyse healing of endoscopic lesions without the confounding that would have occurred if unresolved dyspepsia had been a frequent cause of treatment failure. This was done both for overall rates of healing and for healing of individual lesions (gastric ulcer, duodenal ulcer, or erosions). The factors entered into the multivariate analysis of healing were those used for analysis of baseline lesions (see above) plus the identity of the lesion at baseline (ulcer with or without erosions versus erosions only), its site, its size (for ulcers), and the trial treatment received.

\section{RESULTS}

\section{Demographic features}

Cohort 1 consisted of 1456 patients analysed in the healing phase of the ASTRONAUT and OMNIUM studies. A total of 183 of these patients were recruited (into the OMNIUM study) from 15 centres, which also participated in the OPPULENT study (recruiting 150 patients). Since these 333 patients were drawn from a common population and entered into either the OMNIUM or OPPULENT study on the basis of the findings at screening endoscopy, they are analysed as one group (cohort 2).

Demographic characteristics of the patients in cohorts 1 and 2 were similar (table 1, fig 2), as was the distribution of 
Table 1 Demographics and baseline characteristics

\begin{tabular}{|c|c|c|c|c|}
\hline & $\begin{array}{l}\text { Cohort } 1 \\
(n=1456)\end{array}$ & $\begin{array}{l}\text { Cohort 1: } \\
\text { H pylori-ve } \\
\left(n=738^{*}\right)\end{array}$ & $\begin{array}{l}\text { Cohort 1: } \\
\text { H pylori +ve } \\
\left(n=571^{*}\right)\end{array}$ & $\begin{array}{l}\text { Cohort } 2 \\
(n=333)\end{array}$ \\
\hline \multicolumn{5}{|l|}{ Age (y) } \\
\hline Mean (SD) & $58(12)$ & 57 (13) & $58(12)$ & 57 (13) \\
\hline Range & $20-85$ & $20-85$ & $23-85$ & $22-85$ \\
\hline Female & $938(64 \%)$ & $68 \%$ & $61 \%$ & $196(59 \%)$ \\
\hline Smokers & $333(23 \%)$ & $21 \%$ & $25 \%$ & 85 (26\%) \\
\hline Previous peptic ulcer & $429(29 \%)$ & $27 \%$ & $35 \%$ & $98(29 \%)$ \\
\hline Previous dyspepsia & 1143 (79\%) & $77 \%$ & $82 \%$ & 284 (85\%) \\
\hline \multicolumn{5}{|l|}{ H pylori status } \\
\hline Unknown & 147 (10\%) & & & 43 (13\%) \\
\hline Negative & $738(51 \%)$ & $100 \%$ & & 192 (58\%) \\
\hline Positive & $571(39 \%)$ & & $100 \%$ & $98(29 \%)$ \\
\hline \multicolumn{5}{|l|}{ Arthritic disease } \\
\hline RA & $583(40 \%)$ & $43 \%$ & $40 \%$ & $140(42 \%)$ \\
\hline $\mathrm{OA}$ & $606(42 \%)$ & $39 \%$ & $42 \%$ & 145 (44\%) \\
\hline Other & $218(15 \%)$ & $15 \%$ & $15 \%$ & $39(12 \%)$ \\
\hline Combination & $49(3 \%)$ & $3 \%$ & $3 \%$ & $9(3 \%)$ \\
\hline \multicolumn{5}{|l|}{ Type of lesion } \\
\hline $0-10$ erosions & - & - & - & $150(45 \%)$ \\
\hline GU & $581(40 \%)$ & $40 \%$ & $39 \%$ & $76(23 \%)$ \\
\hline $\mathrm{GU}+\mathrm{DU}$ & $55(4 \%)$ & $3 \%$ & $5 \%$ & $11(3 \%)$ \\
\hline DU & $304(21 \%)$ & $16 \%$ & $27 \%$ & $40(12 \%)$ \\
\hline Erosions only $(\geqslant 11)$ & $516(35 \%)$ & $41 \%$ & $30 \%$ & $56(17 \%)$ \\
\hline \multicolumn{5}{|l|}{ NSAIDs (DDD) } \\
\hline Uncertain $†$ & $149(10 \%)$ & $12 \%$ & $9 \%$ & 45 (14\%) \\
\hline $0-1$ & $561(39 \%)$ & $34 \%$ & $45 \%$ & 112 (34\%) \\
\hline$>1$ & $746(51 \%)$ & $54 \%$ & $46 \%$ & $176(53 \%)$ \\
\hline Steroids & $250(17 \%)$ & $20 \%$ & $15 \%$ & $54(16 \%)$ \\
\hline \multicolumn{5}{|c|}{$\begin{array}{l}\text { *Helicobacter pylori status unknown in } 147 \text { patients. } \\
\text { tln these patients NSAID medication data were too incomplete to derive a DDD of NSAID. } \\
\text { OA, osteoarthritis RA, rheumatoid arthritis; GU, gastric ulcer; DU, duodenal ulcer; NSAIDs, non-steroidal } \\
\text { anti-inflammatory drugs; DDD, defined daily dose. }\end{array}$} \\
\hline
\end{tabular}

clinically significant lesions. Of the 1456 patients analysed in cohort 1, 940 had ulcers (65\%) and 516 had multiple erosions only as their primary lesion at entry. Among those with ulcers, 636 had a gastric ulcer (68\%) and 359 a duodenal ulcer (38\%); gastric ulcers and duodenal ulcers coexisted in $55(6 \%)$ of these patients. A very similar pattern was seen in patients in cohort 2. Of those with clinically significant lesions $69 \%$ had ulcers and, of these, $69 \%$ were gastric ulcers, suggesting that the population from which cohort 2 was drawn was similar to the larger population from which cohort 1 was drawn (fig 2). Most ulcers (83\%) were $\geqslant 5 \mathrm{~mm}$.

\section{Factors associated with clinically significant lesions at baseline}

Sixty four per cent of smokers had clinically significant baseline lesions (ulcers or multiple erosions) compared with 52\% of non-smokers (OR 1.87, 95\% CI 1.07-3.34) (fig 3A). Significant baseline lesions tended to be more common in older than younger patients $(61 \%$ in those $\geqslant 60$ years $v 50 \%$ in those $<60$ years) and in men (62\%) than women (50\%), with more duodenal ulcers in men $(26 \%)$ than women $(8 \%)$. However, these trends fell short of statistical significance (fig 3A).

\section{Factors associated with ulcers versus erosions at baseline}

Among those with clinically significant lesions, logistic regression analysis identified older age, past ulcer history, rheumatoid arthritis, and $H$ pylori infection as significantly associated with ulcers at baseline compared with multiple erosions (fig 3B). There was a trend to more ulcers in those using higher NSAID doses (fig 3B). Among those with ulcers, past ulcer history, H pylori, and male sex were associated with duodenal ulcer while older age, female sex, and higher NSAID dose were associated with gastric ulcer (fig 3C). Neither the individual NSAID used nor coprescription of corticosteroids influenced the overall risk of finding lesions at baseline or the specific ulcer type.

\section{Factors associated with duodenal ulcer (fig $3 \mathrm{C}$ )} H pylori

Ulcers were significantly more common in patients infected with $H$ pylori $(71 \%)$ than in H pylori negative patients $(59 \%$; OR

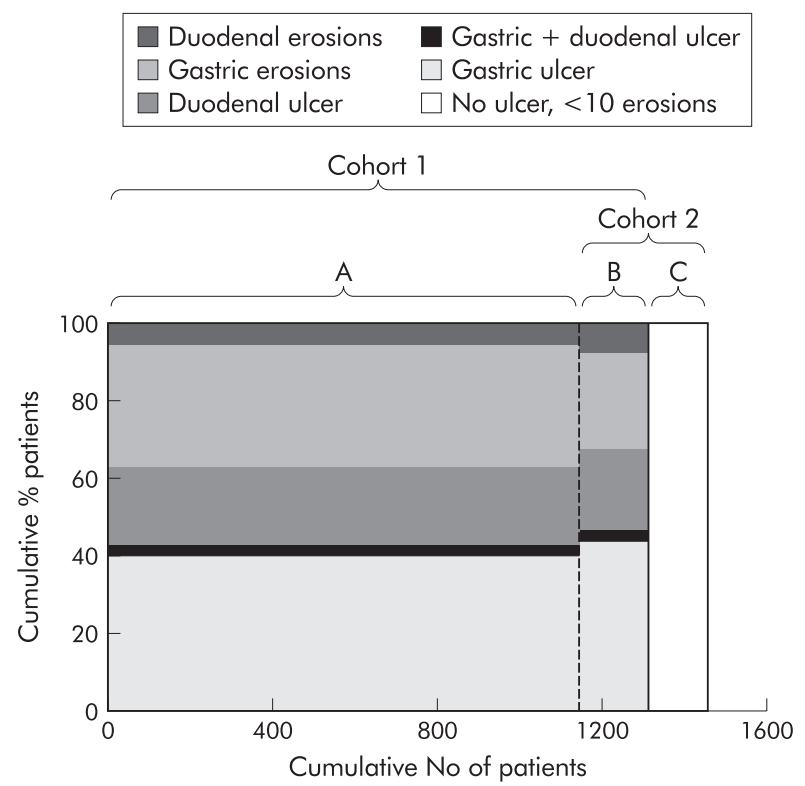

Figure 2 (A) Endoscopic diagnoses in individual patient populations contributing to those analysed. All patients in the OMNIUM and ASTRONAUT centres that did not participate in the OPPULENT study. (B) All patients in the OMNIUM centres who also enrolled patients into the OPPULENT study. (C) All patients enrolled into the OPPULENT study. Cohort 1 is all patients in the OMNIUM and ASTRONAUT studies. Cohort 2 is all patients recruited into either the OMNIUM or OPPULENT studies in dual participation centres. 


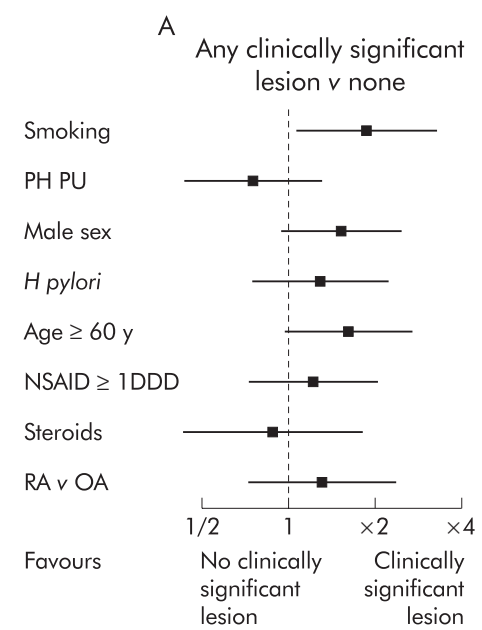

A
B

Ulcer $v$ erosions

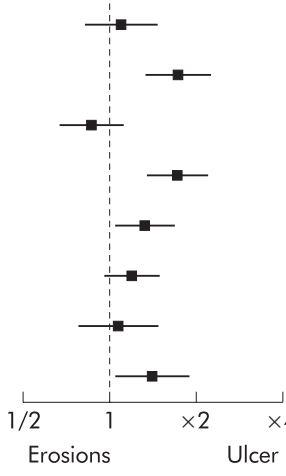

Odds ratio
C GU v DU

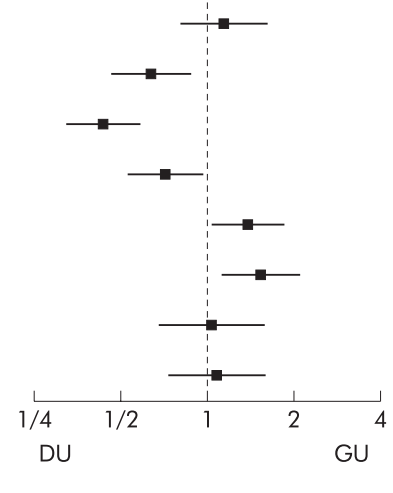

Figure 3 Effect of potential risk factors on endoscopic findings. Influences are expressed as odds ratios with $95 \%$ confidence intervals. Data concerning any clinically significant lesions versus none (A) are from cohort 2. Data concerning ulcer versus erosions (B) and gastric ulcer (GU) versus duodenal ulcer (DU) (C) are from cohort 1. Except where indicated, comparison is with all patients without the stated risk factor. RA rheumatoid arthritis; OA, osteoarthritis; PH PU, past history of peptic ulcer; NSAID, non-steroidal anti-inflammatory drug; DDD, defined daily dose.

$1.73,95 \%$ CI 1.36-2.21). This was attributable to an increased prevalence of duodenal ulceration (32\% of $H$ pylori positive $v$ $19 \%$ of $H$ pylori negative patients; OR 1.41, 95\% CI 1.04-1.93). Nevertheless, $H$ pylori negative individuals accounted for $43 \%$ of all duodenal ulcers.

\section{Sex}

A total of 150 of 518 men (29\%) had a duodenal ulcer only compared with 154 of 938 women (16\%), representing an OR of 2.40 (95\% CI 1.78-3.25) for finding a duodenal ulcer in men compared with women. Duodenal ulcer was commoner in men than women in $H$ pylori negative $(22 \% v 13 \%)$ as well as H pylori positive $(35 \% \vee 21 \%)$ patients. Men were also significantly more likely than women to have duodenal versus gastric erosions (see below).

Peptic ulcer history

Patients with a peptic ulcer history were more likely to have an ulcer than multiple erosions (OR 1.73, 95\% CI 1.34-2.25). Among those with ulcers, those with a past ulcer history were more likely to have a duodenal ulcer $(40.8 \%$ of ulcers $v 28.1 \%$ of ulcers in those without a past ulcer history; OR for duodenal ulcer $v$ gastric ulcer $1.61,95 \% 1.18-2.22$ )

\section{Factors associated with gastric ulcer (fig 3C) \\ Age}

Patients aged $\geqslant 60$ years were significantly more likely to have an ulcer than erosions compared with those $<60$ years of age, although the difference was not large (67\% v 62\%; OR 1.29, $95 \%$ CI $1.02-1.63)$. Patients $\geqslant 60$ years were more likely to have a gastric ulcer (71\% of ulcers) than a duodenal ulcer ( $29 \%$ of ulcers) compared with those $<60$ years (64\% gastric ulcer, $36 \%$ duodenal ulcer; OR for gastric ulcer $v$ duodenal ulcer in older patients $1.37,95 \% 1.01-1.86$ ).

H pylori.

The prevalence of gastric ulcers was similar among $H$ pylori negative $(43 \%)$ and positive $(44 \%)$ patients.

\section{NSAID dose}

Patients taking $>1$ DDD of NSAID were more likely to have a gastric ulcer $(71 \%)$ than those taking lower doses $(59 \%$; OR $1.57,95 \%$ CI $1.16-2.14)$.

\section{Duodenal versus gastric erosions}

In patients entering the trials because of numerous erosions, the stomach was the commonest site (31\% v 7\% duodenal). $H$ pylori infection was associated with a reduction in gastric erosions $(25 \% v 37 \%)$. As with ulcers, duodenal erosions were more common in men than women (OR 2.30, 95\% CI $1.30-4.09)$.

\section{Factors associated with successful treatment (fig 4)}

Patients receiving the different trial drugs were well balanced for all predefined demographic and disease variables. Within each trial, NSAID use was similarly well balanced. However, the individual NSAIDs used differed between the two trials, reflecting different patterns of prescribing in the different participating countries. The NSAIDs most commonly used in the OMNIUM trial were diclofenac (23\%), naproxen $(22 \%)$, and ketoprofen $(16 \%)$, and in the ASTRONAUT trial diclofenac $(29 \%)$, indomethacin $(23 \%)$, and naproxen (16\%).

\section{Overall treatment success}

Overall treatment was more likely to be successful (no ulcer, less than five erosions, and no more than mild dyspepsia) in patients who had gastric erosions or duodenal ulcer at baseline compared with those with gastric ulcer (fig 4). The chance of overall treatment success was lower in men than women (OR 0.79 , 95\% CI $0.63-0.98$ ) and in those taking higher doses of NSAIDs $(0.67,95 \%$ CI $0.54-0.84)$ (fig 4). These differences appeared to be attributable to delayed healing of erosions (fig 4). Treatment success was also more likely to fail in $H$ pylori negative compared with positive patients, reflecting an increased likelihood of gastric ulcer healing in uninfected patients (fig 4). Overall treatment success was significantly greater with omeprazole $20 \mathrm{mg}$ than with ranitidine, and similar to misoprostol (although this varied with individual lesions, see below).

Healing of specific lesions

Figure 4 shows the relationship of prognostic factors to healing of specific lesions.

Gastric ulcers

Large ulcers ( $>10 \mathrm{~mm}$ ) took longer than smaller ulcers to heal ( $49 \% \vee 70 \%$ at four weeks, $71 \% \vee 82 \%$ at eight weeks; OR 0.37 , 95\% CI 0.25-0.54). Healing was also slower if patients reported a past ulcer history (54\% v68\% at four weeks, $72 \% v$ 


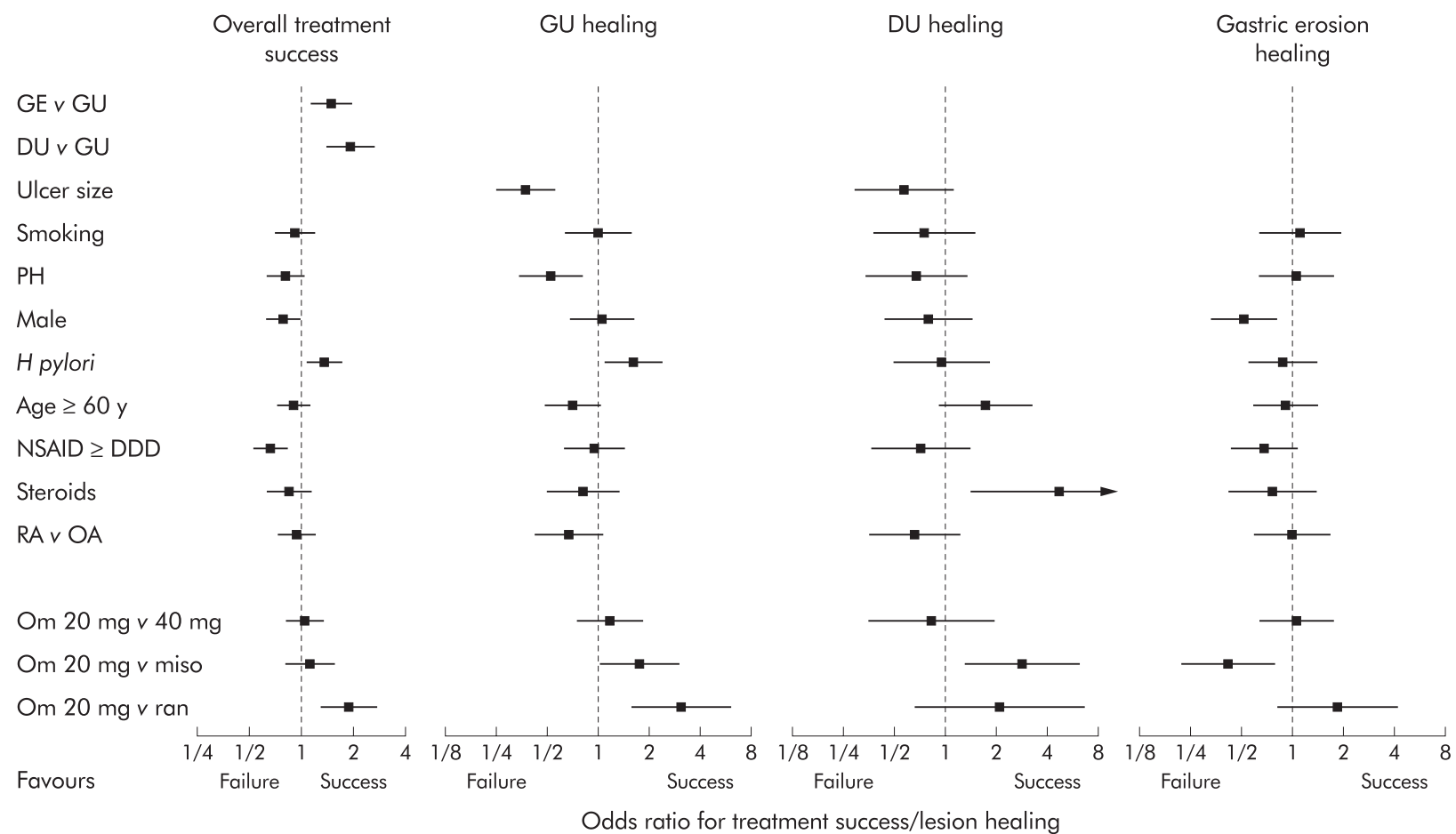

Figure 4 Effect of potential influences on treatment success or ulcer healing over eight weeks. Except where indicated, comparison is with all patients without the stated risk factor. GE, gastric erosions; GU, gastric ulcer; DU, duodenal ulcer; PH, past history; NSAID, non-steroidal anti-inflammatory drug; DDD, defined daily dose; RA, rheumatoid arthritis; OA, osteoarthritis; Om 20, omeprazole 20 mg; Om 40, omeprazole $40 \mathrm{mg}$; Miso, misoprostol $200 \mu \mathrm{g}$ four times daily; Ran, ranitidine $150 \mathrm{mg}$ twice daily.

$82 \%$ at eight weeks; OR 0.51, 95\% CI 0.34-0.76). Conversely, healing tended to be faster with $H$ pylori infection $(66 \%$ v $61 \%$ at four weeks, $76 \% \vee 84 \%$ at eight weeks; OR $1.55,95 \%$ CI 1.06-2.29)

Gastric ulcer healing was significantly faster on omeprazole $20 \mathrm{mg}$ than ranitidine (69\% $v 50 \%$ at four weeks, $86 \%$ v $64 \%$ at eight weeks; OR 2.94, 95\% CI 1.54-5.56). A comparison of gastric ulcer healing rates with misoprostol versus omeprazole $20 \mathrm{mg}$ (62\% v 69\% at four weeks, 73\% v 86\% at eight weeks) fell just short of statistical significance (OR 0.59, 95\% CI 0.351.00 ). Healing rates on omeprazole $40 \mathrm{mg}$ daily were not significantly different from those on omeprazole $20 \mathrm{mg}$ daily.

Duodenal ulcers

In contrast with gastric ulcers, ulcer size, past ulcer history, and $H$ pylori were not significant influences on the rate of duodenal ulcer healing (fig 4). Corticosteroid use appeared to be associated with significantly faster duodenal ulcer healing (93\% v 76\% at four weeks, $96 \%$ v 85\% at eight weeks; OR 4.68, 95\% CI 1.44-21.3) compared with non-use of such medication. As we had no prior hypothesis about this, the result should be considered a hypothesis for further study.

Healing with omeprazole $20 \mathrm{mg}$ was significantly faster than with misoprostol ( $83 \% v 60 \%$ at four weeks, $93 \% \vee 78 \%$ at eight weeks; OR 2.86, 95\% CI 1.25-6.67). The difference between ranitidine and omeprazole did not reach statistical significance $(74 \% \vee 83 \%$ at four weeks, $81 \% \vee 93 \%$ at eight weeks; OR 0.47, 95\% CI 0.16-1.39). Duodenal ulcer healing on omeprazole $40 \mathrm{mg}$ daily was not significantly different from that seen on omeprazole $20 \mathrm{mg}$ daily.

\section{Gastric erosions}

Men had slower healing of gastric erosions $(74 \%$ at eight weeks) compared with women (86\%; OR 0.54, 95\% CI $0.35-0.83)$, as did those taking $>1$ DDD of NSAIDs $(79 \%$ at eight weeks) compared with those taking lower doses $(88 \%$; OR 0.69, 95\% CI 0.45-1.06) (fig 4).
Healing of gastric erosions was faster in patients receiving misoprostol compared with omeprazole $20 \mathrm{mg}$ (OR 2.32, 95\% CI 1.27-4.37).

\section{Interaction between $\boldsymbol{H}$ pylori and individual healing agents}

$H$ pylori had a significant effect on healing of gastric ulcers but not duodenal ulcers or gastric erosions (figs 4, 5). It appeared to enhance healing by acid suppression but retard healing by misoprostol. However, the difference only reached statistical significance in patients receiving ranitidine (72\% v 37\% at four weeks, $84 \% v 51 \%$ at eight weeks; OR 4.66, 95\% CI 1.69-14.07) (fig 5). Healing of large gastric ulcers (>10 mm) was retarded, particularly in $H$ pylori negative patients (overall $34.1 \%$ at four weeks for $H$ pylori negative and $46.2 \%$ for $H$ pylori positive).

\section{DISCUSSION}

One problem in assessing the effects of NSAIDs in endoscopic studies is patient selection. Most studies have reported data concerning patients presenting for endoscopy where selection on clinical grounds may strongly influence the pattern of lesion detected. In our studies we employed an active recruitment policy. Although it is known that low level dyspeptic symptoms may influence the willingness of patients to participate in endoscopically controlled NSAID studies, it is nevertheless likely that our data would be similar to those found in an entirely unselected population as such low level symptoms do not appear to have a major effect on the likelihood of finding endoscopic lesions. ${ }^{26}$ The data presented for cohort 2 are essentially derived from a group of patients eligible to enter one of the studies in our programme of research regardless of their endoscopic findings. These patients in cohort 2 had similar demographic and endoscopic findings with comparable patients in the major study population, suggesting that the data on patients with lesions are representative of such patients in a wider population. 
H pylori negative

H pylori positive

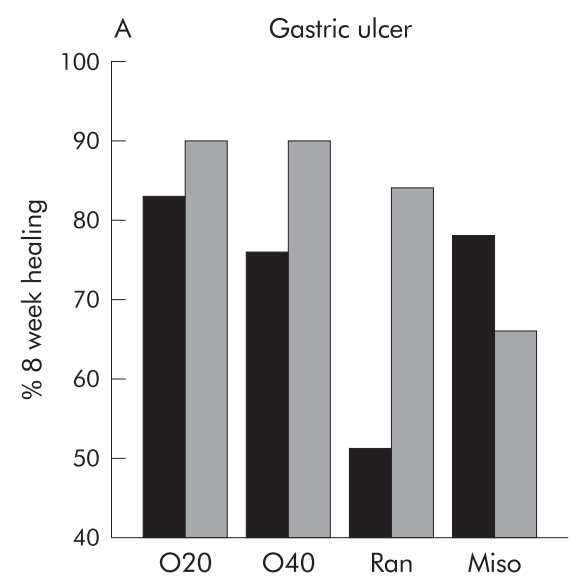

B

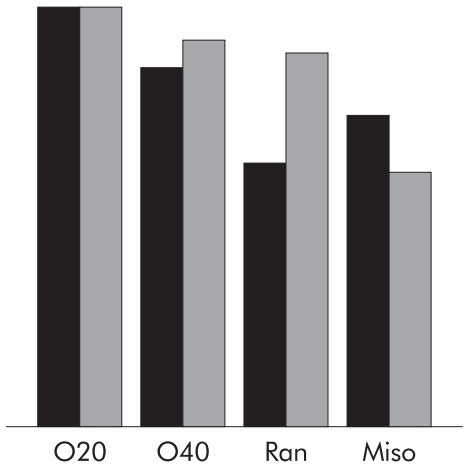

C

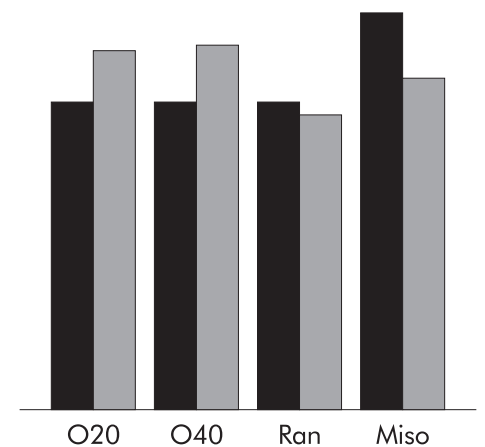

Figure 5 Healing of individual lesions by Helicobacter pylori status. O20, omeprazole 20 mg daily; O40, omeprazole 40 mg daily; Miso, misoprostol 200 jg four times daily; Ran, ranitidine 150 mg twice daily. (Note the Y axis starts at $40 \%$.)

The most striking results from our analysis of baseline data suggest that sex and $H$ pylori status are the main influences on the type of lesions seen in patients using NSAIDs. Male sex and $H$ pylori both appeared to act independently to increase the chances of ulceration compared with erosions and to favour localisation of both ulcers and erosions to the duodenum compared with the stomach. Previous studies of ulcer patients showing male predominance for duodenal ulcer disease $e^{27-33}$ have not been able to separate the influence of sex from higher $H$ pylori infection rates in men. Possible mechanisms include protection of women against duodenal ulceration by oestrogens. ${ }^{34}{ }^{35}$ Although most of our patients were postmenopausal, prior ulceration enhances the risks of site specific recurrence. ${ }^{19} 2036$ Another factor may relate to effective dose in our studies; women received the same defined daily dose of NSAID (mean 1.52 (SD 0.82)) as men ( $1.56(0.94)$ ), representing a $12.6 \%$ higher dose per body weight, which may enhance the risk of gastric ulcer as it is dose dependent. Against these fundamental sex differences, $H$ pylori further modulates the pattern of disease expression by promoting duodenal pathology by the same mechanisms that act in patients not using NSAIDs, while protecting against NSAID specific gastric lesions, for example by promoting prostaglandin synthesis. ${ }^{37}$ Despite the association with $H$ pylori, $43 \%$ of all duodenal ulcers occurred in patients not infected with $H$ pylori showing that NSAIDs can cause both gastric and duodenal ulcers in its absence. This undermines previous arguments that the effects of NSAIDs in duodenal ulcer disease are simply to exacerbate previous ulceration. ${ }^{38}$

As in previous studies, ${ }^{39}$ treatment was overall more likely to be successful for duodenal ulcers than gastric ulcers, and also with multiple erosions as the only lesion. However, healing of erosions was less likely to be successful if high doses of NSAIDs were used. The other significant non-drug influences on lesion healing were ulcer size, past ulcer history, age, $H$ pylori, sex, and steroids. Gastric ulcer healing was retarded with larger ulcers, a past history of ulceration, and in older patients, and was accelerated by $H$ pylori infection. Most ulcers were $\geqslant 5 \mathrm{~mm}$. Apart from retardation of healing, there was little evidence that the pattern of disease with larger ulcers differed from the group overall, although the relatively small number of 3-4 mm ulcers means we cannot be sure that these small ulcers behave differently from what we report here.

Why healing of erosions (but not other lesions) was slower in men than women is unclear and this may have been a chance finding. Also, apparently paradoxical was the finding that healing of duodenal ulcers was faster in patients taking corticosteroids. At first sight, this finding may appear to conflict with previous studies suggesting that use of corticosteroids magnifies the risk of ulcer complications in patients taking NSAIDs. ${ }^{40}$ However, in our studies, patients receiving corticosteroids could only enter if they were using low doses equivalent to $10 \mathrm{mg}$ of prednisolone or less while epidemiological data suggest a greater adverse effect with higher doses. ${ }^{40}$ In experimental ulcers caused by trinitrobenzene, corticosteroids have been reported to improve healing rates, ${ }^{41}$ although the mechanism is not known. These apparent phenomena should be regarded as hypotheses for future study.

The finding that omeprazole was more effective than misoprostol in healing ulcers while the reverse was true for gastric erosions strongly supports previous suggestions of a two component process in the development of NSAID associated ulcer disease. ${ }^{19}{ }^{42}$ Animal studies suggest that prostaglandins maintain gastric mucosal barrier function, possibly as a result of their influence on microvascular flow ${ }^{43}$ and by paracrine influences from myofibroblasts. ${ }^{44}$ Inhibition of prostaglandin synthesis by NSAIDs leads to early microscopic breaches of the mucosa. ${ }^{42}$ These subsequently progress by a process of deepening under the influence of acid peptic attack in the stomach or other factors such as infection in the small intestine. ${ }^{42}$ In the stomach, it appears necessary to reach a $\mathrm{pH}$ minimum of four to prevent this acid peptic attack, ${ }^{45}$ an observation consistent with the greater effect of omeprazole than ranitidine on both ulcers and erosions. Other studies suggest that higher than normal doses of $\mathrm{H}_{2}$ antagonists are of greater efficacy than seen in our studies. The importance of achieving quite profound inhibition of acid would also explain why acid suppression was more effective in $H$ pylori positive patients as it causes a much greater reduction in intragastric acidity in such patients. ${ }^{46}$ Whether NSAID associated ulcers would heal faster and remain in remission more securely if treated with both acid suppression and misoprostol, perhaps in low doses, is not known but plausible and worth investigation.

\section{Authors' affiliations}

C J Hawkey, Division of Gastroenterology, University Hospital Nottingham, Queen's Medical Centre, Nottingham, UK

I Wilson, J Næsdal, G Långström, AstraZeneca R\&D Mölndal, S-43

83 Mölndal, Sweden

A J Swannell, Rheumatology Department, City Hospital, Hucknall Road, Nottingham NG5 1PB, UK

N D Yeomans, Department of Medicine, University of Melbourne, Western Hospital, Footscray, Victoria 3011 , Australia 
Conflict of interest: C J Hawkey has received research funding and/or honoraria from: AstraZeneca, Alizyme, Boehringer Ingelheim, Glaxo Wellcome, Merck, NicOx, Novartis, Parke Davis, Searle, SmithKline

Beecham, and Wyeth Lederle.

\section{REFERENCES}

1 Hawkey CJ. Non steroidal anti-inflammatory drugs and peptic ulcers. Facts and figures multiply, but do they add up? BM 1990;300:278-84

2 Gabriel SE, Jaakkimainen L, Bombardier C. Risk for serious gastrointestinal complications related to use of nonsteroidal anti-inflammatory drugs: a meta-analysis. Ann Intern Med 1991;115:787-96

3 Wolfe MM, Lichtenstein DR, Sing G. Gastrointestinal toxicity of non-steroidal anti-inflammatory drugs. N Eng J Med 1999;340:188899 .

4 Hernandez-Diaz S, Rodriguez LA. Association between nonsteroidal anti-inflammatory drugs and upper gastrointestinal tract bleeding/perforation: an overview of epidemiologic studies published in the 1990s. Arch Intern Med 2000;160:2093-9.

5 Tramer MR, Moore RA, Reynolds DJM, et al. Quantitative estimation or rare adverse events which follow a biological progression. A new model applied to chronic NSAID use. Pain 2000;85:169-82.

6 Fries JF, Williams CA, Bloch DA, et al. Non-steroidal anti-inflammatory drug-associated gastropathy: incidence and risk factor models. Am J Med 1991:91:213-22.

7 Smalley WE, Ray WA, Daugherty JR, et al. Nonsteroidal anti-inflammatory drugs and the incidence of hospitalizations for peptic ulcer disease in elderly persons. Am J Epidemiol 1995;141:539-45.

8 Sun DCH, Roth SH, Mitchell CS, et al. Upper gastrointestinal disease in rheumatoid arthritis. Am J Dig Dis 1974;19:405-10.

9 Geis GS, Stead H, Wallemark C-B, et al. Prevalence of mucosal lesions in stomach and duodenum in patients with rheumatoid arthritis or osteoarthritis and interim report on prevention by misoprostol of diclofenac associated lesions. J Rheumatol 1991;28(suppl): 11-14.

10 Hawkey CJ, Hudson N. Mucosal injury caused by drugs, chemicals and stress. In: Haubrich WS, Schaffner F, Berk JE, eds. Bockus Gastroenterology, 5th edn. Philadelphia: WB Saunders, 1994:656-99.

11 Langman MJS, Weil J, Wainwright $P$, et al. Risk of bleeding peptic ulcer associated with individual non-steroidal anti-inflammatory drugs. Lancet 1994;343:1075-8

12 Garcia Rodriguez LA, Jick H. Risk of upper gastrointestinal bleeding and perforation associated with individual non-steroidal anti-inflammatory drugs. Lancet 1994;343:769-72.

13 Henry D, Lim LL-Y, Rodriguez LAG, et al. Variability in risk of gastrointestinal complications with individual non-steroidal anti-inflammatory drugs: results of a collaborative meta-analysis. BM 1996;312:1563-6

14 Simon LS, Weaver AL, Graham DY, et al. Anti-inflammatory and upper gastrointestinal effects of celecoxib in rheumatoid arthritis. JAMA 1999;282:1921-8.

15 Laine L, Harper S, Simon T, et al. A randomized trial comparing the effect of rofecoxib, a cyclooxygenase-2 specific inhibitor, with that of ibuprofen on the gastroduodenal mucosa of patients with osteoarthritis. Gastroenterology 1999;117:776-83.

16 Emery P, Zeidler H, Kvien TK, et al. Celecoxib versus diclofenac in long-term management of rheumatoid arthritis: randomised double-blind comparison. Lancet 1999;354:2106-11.

17 Hawkey CJ, Laine I, Simon T, et al. Comparison of the effect of rofecoxib (a cyclooxygenase 2 inhibitor), ibuprofen and placebo on the gastroduodenal mucosa of patients with osteoarthritis. Arthritis Rheum 2000;43:370-7

18 Ekstrom P, Carling L, Wetterhus S, et al. Prevention of peptic ulcer and dyspeptic symptoms with omeprazole in patients receiving continuous non-steroidal anti-inflammatory drug therapy. A Nordic multicentre study. Scand J Gastroenterol 1996;31:753-8

19 Hawkey CJ, Karrasch JA, Szczepanski L, et al. Omeprazole compared with misoprostol for ulcers associated with nonsteroidal antiinflammatory drugs. N Engl J Med 1998;338:727-34.
20 Yeomans ND, Tulassay Z, Juhasz L, et al. A comparison of omeprazole and ranitidine for treating and preventing ulcers associated with non-steroidal anti-inflammatory drugs. New Engl J Med 1998;338:719-26.

21 Cullen D, Bardhan DK, Eisner M, et al. Primary gastroduodenal prophylaxis with omeprazole for non-steroidal anti-inflammatory drug users. Aliment Pharmacol Ther 1998;12:135.

22 Hawkey CJ, Tulassay Z, Szczepanski L, et al. Helicobacter pylori eradication in patients taking non-steroidal, anti-inflammatory drugs: The HELP NSAIDs Study. Lancet 1998;352:1016-21.

23 Hawkey CJ, Næsdal J, Wilson I, et al. Relative contribution of mucosal injury and Helicobacter pylori in the development of gastroduodenal lesions in patients taking non-steroidal anti-inflammatory drugs. Gut 2002;51:336-43.

24 Hosmer DW Jr, Lemeshow S. Applied Logistic Regression. New York: John Wiley and Sons, 1984

25 World Health Organisation Collaborating Centre for Drug Statistics Methodology. Guidelines for defined daily doses. Oslo: World Health Organisation, 1991

26 Hudson N, Everitt SJ, Taha AS, et al. Self-selection for endoscopic surveys in patients on NSAIDs. Gut 1990;31:A1 177

27 Pulvertaft CN. Peptic ulcer in town and country. Br J Prev Soc Med 1959;13:131.

28 Fry J. Peptic ulcer: a profile. BM 1964;2:809-12

29 Bonnevie O. The incidence of duodenal ulcer in Copenhagen county. Scand J Gastroenterol 1975;10:385-93.

30 Johnsen R, Bernersen B, Straume B, et al. Prevalences of endoscopic and histological findings in subjects with and without dyspepsia. $B M$ 1991;302:749-52.

31 Kaneko E, Ooi S, Ito $G$, et al. Natural history of duodenal ulcer detected by the gastric mass surveys in men over 40 years of age. Scand J Gastroenterol 1989:24:165-70.

32 Lam SK, Hui WM, Ching CK. Peptic ulcer disease: epidemiology, pathogenesis and etiology. In: Haubrich WS, Schaffner F, Berk JE, eds. Bockus Gastroenterology, 5th edn. Philadelphia: WB Saunders 1994:700-48.

33 Coggon D, Lambert $P$, Langman M. 20 years of hospital admissions for peptic ulcer in England and Wales. Lancet 1981;1:1302-4.

34 Truelove SC. Stiboestrol, phenobarbitone and diet in chronic duodenal ulcer. BM 1960;2:559-66.

35 Anonyomous. Sex differences in duodenal ulcer. BM 1979;1:641-2.

36 Hawkey CJ, Harper SE, Quan H, et al. Effect of rofecoxib on endoscopic ulcers in osteoarthritis patients: analysis of potential risk factors. Ann Rheum Dis 2000;59(suppl):290.

37 Hudson N, Balsitis M, Filipowicz B, et al. Effect of Helicobacter pylori colonisation on gastric mucosal eicosanoid synthesis in patients taking non-steroidal anti-inflammatory drugs. Gut 1993;34:748-51.

38 Shorrock CJ, Langman M. Nonsteroidal anti-inflammatory drug-induced gastric damage: epidemiology. Dig Dis Sci 1995;13(suppl 1):3-8.

39 Lancaster-Smith MJ, Jaderberg ME, Jackson DA. Ranitidine in the treatment of non-steroidal anti-inflammatory drug-associated gastric and duodenal ulcers. Gut 1991;32:252-5.

40 Piper JM, Ray WA, Daugherty JR, et al. Corticosteroid use and peptic ulcer disease: role of nonsteroidal anti-inflammatory drugs. Ann Intern Med 1991;114:735-40.

41 Wallace JL, Whittle BJ. Effects of inhibitors of arachidonic acid metabolism on Paf-induced gastric mucosal necrosis and haemoconcentration. Br J Pharmacol 1986;89:415-22.

42 Whittle BJ. Temporal relationship between cyclooxygenase inhibition, as measured by prostacyclin biosynthesis, and the gastrointestinal damage induced by indomethacin in the rat. Gastroenterology 1981;80:94-8.

43 Hawkey CJ. Nonsteroidal anti-inflammatory drug gastropathy. Gastroenterology 2000;1 19:521-35

44 Powell DW, Mifflin RC, Valentich JD, et al. Myofibroblasts. II. Intestinal subepithelial myofibroblasts. Am J Physiol 1999;277:C183-201.

45 Elliott SL, Ferris RJ, Giraud AS, et al. Indomethacin damage to rat gastric mucosa is markedly dependent on luminal pH. Clin Exp Pharmacol Physiol 1996;23:432-4

46 Labenz J, Tillenburg B, Peitz U, et al. Effect of curing Helicobacter pylori infection on intragastric acidity during treatment with ranitidine in patients with duodenal ulcer. Gut 1997;41:33-6. 